\title{
The Matching Research of Strawberry Diseases Image Features Based on KD-Tree Search Method
}

\author{
Chen Jianshu, Wang Jianlun*, Wang Shuting, and Liu Hao \\ College of Information and Electrical Engineering, China Agricultural University, \\ Beijing 100083, P.R. China \\ wangjianlun@cau.edu.cn
}

\begin{abstract}
According to the problem of the low matching accuracy rate and the low speed in the matching technology for image search, we choose the image of the strawberry diseases as the object of the research, to extract the feature of strawberry diseases image and then do cluster analysis using SPSS, and choose the feature combination according to the clustering effect. Do search matching experiments on the feature combination by KD-Tree matching algorithm respectively, and determine the characteristics combination which search matching accuracy is higher by comparing the results. This feature combination of strawberry powdery mildew matching accuracy reached $83.3 \%$, the deformity of strawberry matching accuracy reached $60.0 \%$, the aim is to provide the research basis for rapid disease diagnosis on strawberry.
\end{abstract}

Keywords: Feature extraction, SPSS, KD-Tree, Search matching, Feature combination.

\section{Introduction}

Corp diseases are easily happens and spreads quickly, and once the disaster occurs it will bring a great loss to farmers. Due to the traditional crop disease and pest database and diagnosis expert system using text description of shape, color, symptoms of crop diseases and insect pests, but the text description is inaccurate and subjective, and will lead to crop pests and diseases diagnosis result deviation and slowly.

With the popularity of hardware equipment and mature technology in image processing, automatic classification, growth monitoring in fruits and vegetables and plant diseases and insect pests prevention, agricultural engineering applications are using various methods based on computer vision technology.

Among them the search based on image feature point matching is one of the most important processes of image matching, and KD-Tree matching search is a commonly used method. For example, Du Zhenpeng image matching for feature detection and matching the search time is long, they do research on the image matching algorithm based on KD-Tree search method and SURF features. The algorithm firstly extracted from SURF image features and generate a feature vector, then the vector to construct

* Corresponding author.

D. Li and Y. Chen (Eds.): CCTA 2013, Part I, IFIP AICT 419, pp. 32-40, 2014.

(C) IFIP International Federation for Information Processing 2014 
KD-Tree index for the feature description, finally calculated the distance of the nearest neighbor for each feature point of a plurality of KD-Tree and finish the work of feature matching[1].Wu Han et.al for miniature in the design of the database engine to achieve a nested query and multi-table join queries introduced KD - Tree, and on the basis of B + Tree is improved, thus to speed up the query speed[2]. J.J. Aguila et.al introduced a parallel implementation of fuzzy neural network method for distributed memory architecture based on the KD tree. This method has good precision and can better realize the fuzzy neural network method based on KD tree, the results of their implementation has good speed and efficiency, particularly in terms of speed, their method is 3 20 times faster than the sequential algorithm [3].

\section{Material and Method}

\subsection{Material}

The characteristic of image content mainly includes three types: color feature, shape feature and texture feature. In this paper we choose strawberry as the object of research, one reason is strawberry is a small berry with high economic value, it has a short growth period, high nutritional value and widely grown in the greenhouse. Another reason is strawberry both have clear characteristics of color and texture. The main object of study is normal strawberry, deformity strawberry and powdery mildew of strawberry. Due to the presence of powdery mildew of strawberry also covers abnormal and normal strawberry shape, therefore, in this study only do the color, texture features extracted and research.Fig.1 shows tree type of strawberry in the research.

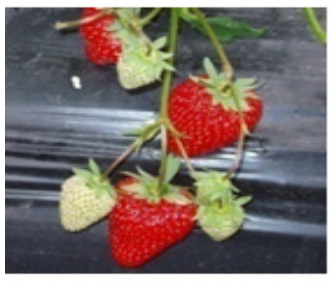

(a) normal

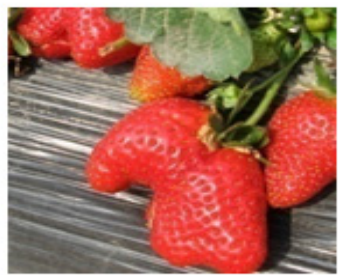

(b) deformity

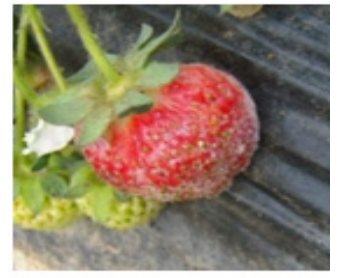

(c) powdery mildew

Fig. 1. Conventional and spectra after pretreatment

For color feature, it mainly contains the RGB and HSI color space[4], according to the analysis results, the mean and variance of the color components of RGB and HSI color space as a characteristic parameter under construction.

For texture feature, Haralick defined 14 gray co-occurrence matrix parameters for texture analysis. But Ulaby research found that Based on 14 texture features in CLCM, only 4 characteristic is not related[5]. These four characteristics is easy to calculate and can give a higher classification accuracy, so this paper uses the following four characteristics of the most commonly used to extract texture features of images: second moment, contrast, correlation, entropy. 


\section{$2.2 \quad$ SPSS}

SPSS is a powerful data analysis software, it is the world's first statistical analysis software, its basic functions include data management, statistical analysis, chart analysis, clustering analysis and so on, in this paper we use the SPSS software of analysis functions.

Clustering is to get a collection of physical or abstract objects into a similar object composed of multiple classes of process, the clustering generated by the cluster is a collection of data objects, these objects with the same object in a cluster are similar to each other, and other objects in different clusters. Clustering of multi-dimensional image features in this paper, analysis that can make a normal and disease samples strawberry good clustering feature descriptor.

\section{$2.3 \quad$ KD-Tree}

KD-Tree (K-dimension tree functions) is a kind of data structure of data points in $\mathrm{K}$ dimensional space division, it was first proposed by Bentle [6], through by extended a binary search tree to high dimension space, realize retrieving multiple attribute data or multidimensional data, its purpose is to search the nearest data point and the query point the distance in the KD-tree, the most commonly used nearest node search algorithm is KNN nearest neighbor node search algorithm [7].

In this paper, characteristics of strawberry image is a set of multidimensional data, mainly through the combination of similarity matching between samples, that is to find the most adjacent nodes and feature point strawberry disease image to realize the rapid diagnosis of diseases of strawberry sample type, in this study using the KD-Tree search matching method. The structure of KD-Tree description as shown in table 1:

Table 1. Description of the KD-Tree data structure

\begin{tabular}{l|l|l}
\hline Domain name & \multicolumn{1}{c}{ Data Type } & \multicolumn{1}{c}{ Description of each domain name } \\
\hline $\begin{array}{l}\text { Range } \\
\text { Split }\end{array}$ & $\begin{array}{l}\text { Data vector } \\
\text { Integer }\end{array}$ & $\begin{array}{l}\text { Data from a data point, is an n-dimensional } \\
\text { vector } \\
\text { The space of the node represents } \\
\text { The axis number perpendicular to the direction } \\
\text { of super split plane } \\
\text { A KD-Tree Composed by all data points } \\
\text { located in the super split plane of left sub-tree } \\
\text { A KD-Tree Composed by all data points } \\
\text { located in the super split plane of right sub-tree } \\
\text { Parent node }\end{array}$ \\
Kaght & KD-Tree \\
\hline
\end{tabular}

KD-Tree search in a small scale space has a very good performance, but when the number of nodes searches exponentially and will increase with dimension as space, especially the dimension is larger than 10 the KD-Tree search will become very slow. When carried out the KD-Tree nearest node searching and matching, the similarity evaluation of two feature vector can be adopted by a Euclidean distance of key point's characteristic as the evaluation standard [8]. 


\section{$3 \quad$ Experiment and Results}

In this paper we uses $\mathrm{C} 1, \mathrm{C} 2, \mathrm{C} 3, \mathrm{C} 4, \mathrm{C} 5, \mathrm{C} 6$ respectively represent the mean and variance of color components in RGB color space , C7, C8, C9, C10, C11, C12 respectively represent the mean and variance of color components in HSI color space for color feature. We uses T1, T2, T3, T4, T5, T6, T7, T8 to respectively represent the two order moment, contrast, correlation, entropy for texture feature.

\subsection{SPSS Cluster Analysis}

According to the color histogram and gray level co-occurrence matrix [9-10] and other methods of strawberry, powdery mildew of strawberry, deformity strawberry and normal strawberry image (for comparison) to extract color features and texture features, each feature clustering results(when the feature quantity of correct classification rate over 60 percent,we think it has a good performance in clustering) for each type of sample (in the divided into a kind of sample volume of the largest class definition for correct classification) statistical results as shown in Table 2, table 3, table 4:

Table 2. The clustering results of normal strawberry characteristic quantity

\begin{tabular}{cccccc}
\hline $\begin{array}{c}\text { Feature } \\
\text { quantity }\end{array}$ & $\begin{array}{c}\text { Number of } \\
\text { samples }\end{array}$ & $\begin{array}{c}\text { Number of } \\
\text { classification }\end{array}$ & $\begin{array}{c}\text { Number of } \\
\text { successful } \\
\text { classification }\end{array}$ & $\begin{array}{c}\text { Number of } \\
\text { unsuccessful } \\
\text { classification }\end{array}$ & $\begin{array}{c}\text { Correct } \\
\text { classification } \\
\text { rate }\end{array}$ \\
\hline C1 & 30 & 13 & 5 & 25 & $16.7 \%$ \\
C2 & 30 & 8 & 10 & 20 & $33.3 \%$ \\
C3 & 30 & 10 & 10 & 20 & $33.3 \%$ \\
C4 & 30 & 4 & 16 & 14 & $53.3 \%$ \\
C5 & 30 & 10 & 10 & 20 & $33.3 \%$ \\
C6 & 30 & 3 & 29 & 1 & $96.7 \%$ \\
C7 & 30 & 6 & 13 & 17 & $43.3 \%$ \\
C8 & 30 & 6 & 15 & 15 & $50.0 \%$ \\
C9 & 30 & 8 & 13 & 17 & $43.3 \%$ \\
C10 & 30 & 16 & 7 & 23 & $23.3 \%$ \\
C11 & 30 & 15 & 5 & 25 & $16.7 \%$ \\
C12 & 30 & 22 & 2 & 28 & $6.7 \%$ \\
T1 & 30 & 5 & 24 & 6 & $80.0 \%$ \\
T2 & 30 & 13 & 13 & 17 & $43.3 \%$ \\
T3 & 30 & 13 & 10 & 20 & $33.3 \%$ \\
T4 & 30 & 11 & 12 & 18 & $40.0 \%$ \\
T5 & 30 & 6 & 15 & 15 & $50.0 \%$ \\
T6 & 30 & 4 & 26 & 4 & $86.7 \%$ \\
T7 & 30 & 14 & 6 & 24 & $20.0 \%$ \\
T8 & 30 & 7 & 22 & 8 & $73.3 \%$ \\
\hline
\end{tabular}

From the table 2, it is clear that four feature quantities(Namely C6,T1,T6,T8) reach a good performance in clustering. 
Table 3. The clustering results of deformity strawberry characteristic quantity

\begin{tabular}{cccccc}
\hline $\begin{array}{c}\text { Feature } \\
\text { quantity }\end{array}$ & $\begin{array}{c}\text { Number of } \\
\text { samples }\end{array}$ & $\begin{array}{c}\text { Number of } \\
\text { classification }\end{array}$ & $\begin{array}{c}\text { Number of } \\
\text { successful } \\
\text { classification }\end{array}$ & $\begin{array}{c}\text { Number of } \\
\text { unsuccessful } \\
\text { classification }\end{array}$ & $\begin{array}{c}\text { Correct } \\
\text { classification } \\
\text { rate }\end{array}$ \\
\hline C1 & 30 & 5 & 16 & 14 & $53.3 \%$ \\
C2 & 30 & 17 & 6 & 24 & $20.0 \%$ \\
C3 & 30 & 15 & 6 & 24 & $20.0 \%$ \\
C4 & 30 & 10 & 8 & 22 & $26.7 \%$ \\
C5 & 30 & 13 & 7 & 23 & $23.3 \%$ \\
C6 & 30 & 13 & 7 & 23 & $23.3 \%$ \\
C7 & 30 & 2 & 29 & 1 & $96.7 \%$ \\
C8 & 30 & 9 & 18 & 12 & $60.0 \%$ \\
C9 & 30 & 10 & 8 & 22 & $26.7 \%$ \\
C10 & 30 & 16 & 2 & 25 & $6.7 \%$ \\
C11 & 30 & 17 & 3 & 27 & $10.0 \%$ \\
C12 & 30 & 3 & 27 & 3 & $90.0 \%$ \\
T1 & 30 & 15 & 7 & 23 & $23.3 \%$ \\
T2 & 30 & 11 & 8 & 22 & $26.7 \%$ \\
T3 & 30 & 9 & 8 & 22 & $26.7 \%$ \\
T4 & 30 & 15 & 9 & 21 & $30.0 \%$ \\
T5 & 30 & 5 & 16 & 14 & $53.3 \%$ \\
T6 & 30 & 11 & 12 & 18 & $40.0 \%$ \\
T7 & 30 & 16 & 3 & 27 & $10.0 \%$ \\
T8 & 30 & 2 & 28 & 2 & $93.3 \%$ \\
\hline
\end{tabular}

Table 4. The clustering results of powdery mildew of strawberry characteristic quantity

\begin{tabular}{cccccc}
\hline $\begin{array}{c}\text { Feature } \\
\text { quantity }\end{array}$ & $\begin{array}{c}\text { Number of } \\
\text { samples }\end{array}$ & $\begin{array}{c}\text { Number of } \\
\text { classification }\end{array}$ & $\begin{array}{c}\text { Number of } \\
\text { successful } \\
\text { classification }\end{array}$ & $\begin{array}{c}\text { Number of } \\
\text { unsuccessful } \\
\text { classification }\end{array}$ & $\begin{array}{c}\text { Correct } \\
\text { classification } \\
\text { rate }\end{array}$ \\
\hline C1 & 30 & 10 & 6 & 24 & $20.0 \%$ \\
C2 & 30 & 6 & 12 & 18 & $40.0 \%$ \\
C3 & 30 & 7 & 11 & 19 & $36.7 \%$ \\
C4 & 30 & 7 & 15 & 15 & $50.0 \%$ \\
C5 & 30 & 8 & 8 & 22 & $26.7 \%$ \\
C6 & 30 & 4 & 19 & 11 & $63.3 \%$ \\
C7 & 30 & 8 & 17 & 13 & $56.7 \%$ \\
C8 & 30 & 12 & 6 & 24 & $20.0 \%$ \\
C9 & 30 & 6 & 10 & 20 & $33.3 \%$ \\
C10 & 30 & 7 & 15 & 15 & $50.0 \%$ \\
C11 & 30 & 5 & 12 & 18 & $40.0 \%$ \\
C12 & 30 & 7 & 19 & 11 & $63.3 \%$ \\
T1 & 30 & 15 & 4 & 26 & $13.3 \%$ \\
T2 & 30 & 16 & 3 & 27 & $10.0 \%$ \\
T3 & 30 & 17 & 5 & 25 & $16.7 \%$ \\
T4 & 30 & 12 & 5 & 25 & $16.7 \%$ \\
T5 & 30 & 10 & 9 & 21 & $30.0 \%$ \\
T6 & 30 & 8 & 18 & 12 & $60.0 \%$ \\
T7 & 30 & 14 & 5 & 15 & $16.7 \%$ \\
T8 & 30 & 2 & 29 & 1 & $96.7 \%$ \\
\hline
\end{tabular}


From the table 3, it is clear that four feature quantities(Namely C7,C8,C12,T8) reach a good performance in clustering.

From the table 4, it is clear that four feature quantities(Namely C6,C12,T6,T8) reach a good performance in clustering.

\subsection{KD-Tree Search Matching}

In this paper we uses 90 strawberry samples(including normal strawberry, strawberry of powdery mildew and deformity strawberry, each type samples includes 30 samples) selected three features to build 3D-Tree, three features to be matched samples of input KD-Tree search matching program. Here similarity evaluation for the two feature vector Euclidean distance metric is a key point features can be used as the evaluation standard. Because the feature vector consists of three parts, and can be set to the feature representing the two nodes. The Euclidean distance between them as follows:

Table 5. The matching results of deformity strawberry

\begin{tabular}{|c|c|c|c|c|c|c|}
\hline \multirow[t]{2}{*}{ Sample } & \multicolumn{3}{|c|}{ Nearest neighbor node coordinates } & \multirow{2}{*}{$\begin{array}{l}\text { Euclidean } \\
\text { distance }\end{array}$} & \multirow{2}{*}{\multicolumn{2}{|c|}{$\begin{array}{l}\text { The Search nodes } \\
\text { and sample type }\end{array}$}} \\
\hline & $\mathrm{X}$-Axis & Y- Axis & Z- Axis & & & \\
\hline sample1 & 0.151583 & 0.114053 & 0.487964 & 0.0498854 & 62 & Normal \\
\hline sample2 & 0.16766 & 0.137424 & 0.872836 & 0.0424372 & 70 & Deformity \\
\hline sample 3 & 0.146195 & 0.117112 & 0.367566 & 0.0249852 & 57 & Deformity \\
\hline sample 4 & 0.276683 & 0.212421 & 0.234173 & 0.0446088 & 37 & Powdery \\
\hline sample 5 & 0.214051 & 0.169284 & 0.594228 & 0.118599 & 69 & Normal \\
\hline sample 6 & 0.107811 & 0.102575 & 0.164185 & 0.016096 & 44 & Deformity \\
\hline sample 7 & 0.152462 & 0.106678 & 0.450741 & 0.0140581 & 59 & Deformity \\
\hline sample 8 & 0.169123 & 0.135545 & 0.502643 & 0.0278196 & 63 & Deformity \\
\hline sample 9 & 0.082651 & 0.0960127 & 0.101104 & 0.00424334 & 36 & Deformity \\
\hline sample 10 & 0.180979 & 0.151676 & 0.526856 & 0.0674990 & 69 & Powdery \\
\hline sample 11 & 0.132939 & 0.101810 & 0.349519 & 0.0580199 & 49 & Deformity \\
\hline sample 12 & 0.142896 & 0.142075 & 0.496051 & 0.0278196 & 60 & Deformity \\
\hline sample 13 & 0.130797 & 0.113844 & 0.327825 & 0.014884 & 50 & Normal \\
\hline sample 14 & 0.157395 & 0.130031 & 0.409041 & 0.0270746 & 59 & Normal \\
\hline sample 15 & 0.130551 & 0.0964061 & 0.160626 & 0.0118761 & 55 & Normal \\
\hline sample 16 & 0.102352 & 0.090021 & 0.172653 & 0.0160960 & 56 & Deformity \\
\hline sample 17 & 0.16314 & 0.132223 & 0.830962 & 0.0424372 & 70 & Deformity \\
\hline sample 18 & 0.13495 & 0.125852 & 0.335578 & 0.0275788 & 61 & Deformity \\
\hline sample 19 & 0.143318 & 0.107794 & 0.390569 & 0.0249852 & 57 & Deformity \\
\hline sample 20 & 0.122062 & 0.107776 & 0.0855459 & 0.0253014 & 41 & Powdery \\
\hline sample 21 & 0.130797 & 0.113844 & 0.327825 & 0.0249000 & 51 & Normal \\
\hline sample 22 & 0.162125 & 0.123367 & 0.0777855 & 0.0301397 & 65 & Normal \\
\hline sample 23 & 0.146915 & 0.113122 & 0.0545784 & 0.0322891 & 52 & Normal \\
\hline sample 24 & 0.116402 & 0.10256 & 0.325141 & 0.00541093 & 45 & Normal \\
\hline sample 25 & 0.163326 & 0.113567 & 0.456412 & 0.0140571 & 53 & Deformity \\
\hline sample 26 & 0.0846707 & 0.0992257 & 0.103003 & 0.00424334 & 35 & Deformity \\
\hline sample 27 & 0.160056 & 0.131389 & 0.325597 & 0.0307228 & 74 & Deformity \\
\hline sample 28 & 0.0846707 & 0.0992257 & 0.103003 & 0.0306622 & 45 & Deformity \\
\hline sample 29 & 0.160056 & 0.131389 & 0.325597 & 0.0175819 & 62 & Deformity \\
\hline sample 30 & 0.180978 & 0.172669 & 0.537890 & 0.0237166 & 53 & Deformity \\
\hline
\end{tabular}




$$
d\left(x_{i}+x_{j}\right)=\sqrt{\left(x_{i 1}-x_{j 1}\right)^{2}+\left(x_{i 2}-x_{j 2}\right)^{2}+\left(x_{i 3}-x_{j 3}\right)^{2}}
$$

Matching results can be obtained by calculating the Euclidean distance nearest neighbor search for matching nodes, and analysis of a representative sample of the node type, whether right or wrong type of samples (mainly through the sample to be matching matches consistent criteria for judging), deformity strawberry and powdery mildew of strawberry search for matching results are shown in table 5, table 6 below:

Table 6. The matching results of powdery mildew of strawberry

\begin{tabular}{|c|c|c|c|c|c|c|}
\hline \multirow{3}{*}{$\begin{array}{l}\text { Sample } \\
\text { Sample1 }\end{array}$} & \multicolumn{3}{|c|}{ Nearest neighbor node coordinates } & \multirow{3}{*}{$\begin{array}{c}\begin{array}{c}\text { Euclidean } \\
\text { distance }\end{array} \\
0.00340927\end{array}$} & \multirow{2}{*}{\multicolumn{2}{|c|}{$\begin{array}{l}\text { The Search nodes } \\
\text { and sample type }\end{array}$}} \\
\hline & \multirow{2}{*}{$\begin{array}{c}\mathrm{X} \text { - Axis } \\
0.150491\end{array}$} & \multirow{2}{*}{$\begin{array}{c}\text { Y- Axis } \\
0.106692\end{array}$} & \multirow{2}{*}{$\begin{array}{c}\text { Z-Axis } \\
0.0466092\end{array}$} & & & \\
\hline & & & & & 42 & Powdery \\
\hline Sample 2 & 0.139989 & 0.109184 & 0.0182249 & 0.0186919 & 47 & Powdery \\
\hline Sample 3 & 0.133554 & 0.120663 & 0.246202 & 0.0125674 & 45 & Powdery \\
\hline Sample 4 & 0.203901 & 0.164683 & 0.381373 & 0.0211159 & 41 & Normal \\
\hline Sample 5 & 0.130551 & 0.0964061 & 0.160626 & 0.0189952 & 54 & Normal \\
\hline Sample 6 & 0.175663 & 0.166097 & 0.49239 & 0.0390932 & 60 & Powdery \\
\hline Sample 7 & 0.149334 & 0.109777 & 0.0474865 & 0.00820598 & 40 & Powdery \\
\hline Sample 8 & 0.121279 & 0.105738 & 0.0778598 & 0.00799019 & 37 & Powdery \\
\hline Sample 9 & 0.143153 & 0.119272 & 0.0277412 & 0.0106403 & 42 & Powdery \\
\hline Sample 10 & 0.153292 & 0.145267 & 0.282223 & 0.0284982 & 66 & Normal \\
\hline Sample 11 & 0.127353 & 0.112451 & 0.242179 & 0.0251362 & 58 & Powdery \\
\hline Sample 12 & 0.0584718 & 0.119704 & 0.0186351 & 0.0106403 & 46 & Powdery \\
\hline Sample 13 & 0.117785 & 0.095876 & 0.0486139 & 0.0069166 & 39 & Powdery \\
\hline Sample 14 & 0.170719 & 0.141748 & 0.0251527 & 0.0250481 & 43 & Powdery \\
\hline Sample 15 & 0.149337 & 0.109777 & 0.0474865 & 0.00340927 & 32 & Powdery \\
\hline Sample 16 & 0.20153 & 0.157729 & 0.492711 & 0.0271892 & 55 & Normal \\
\hline Sample 17 & 0.180979 & 0.151676 & 0.526856 & 0.0237166 & 55 & Powdery \\
\hline Sample 18 & 0.146915 & 0.113122 & 0.0545784 & 0.0115159 & 44 & Powdery \\
\hline Sample 19 & 0.171319 & 0.132066 & 0.0282659 & 0.0101883 & 42 & Powdery \\
\hline Sample 20 & 0.133554 & 0.120663 & 0.246202 & 0.0110485 & 41 & Powdery \\
\hline Sample 21 & 0.133554 & 0.120663 & 0.246202 & 0.0110485 & 41 & Powdery \\
\hline Sample 22 & 0.273167 & 0.201867 & 0.277682 & 0.0449088 & 36 & Deformity \\
\hline Sample 23 & 0.127353 & 0.112451 & 0.242179 & 0.0110485 & 32 & Powdery \\
\hline Sample 24 & 0.170719 & 0.141748 & 0.0251527 & 0.0101883 & 44 & Powdery \\
\hline Sample 25 & 0.120286 & 0.0922447 & 0.0432852 & 0.0069116 & 36 & Powdery \\
\hline Sample 26 & 0.14864 & 0.119704 & 0.0186351 & 0.0136266 & 47 & Powdery \\
\hline Sample 27 & 0.196121 & 0.169159 & 0.0556842 & 0.0141064 & 36 & Powdery \\
\hline Sample 28 & 0.122062 & 0.107776 & 0.0855459 & 0.00799019 & 38 & Powdery \\
\hline Sample 29 & 0.197011 & 0.15916 & 0.0457738 & 0.0141064 & 38 & Powdery \\
\hline Sample 30 & 0.121279 & 0.105738 & 0.0778598 & 0.0147406 & 54 & Powdery \\
\hline
\end{tabular}

For the deformity strawberry image feature points to the adjacent node searching, the number of matching correct results is 18 , incorrect is 12 , the search matching accuracy is $60 \%$; For each samples of powdery mildew of strawberry image feature points to the adjacent node searching, the number of matching the correct result is 25 , incorrect is 5, the search matching accuracy is $83.3 \%$. 


\section{Discussion and Conclusion}

\subsection{Discussion}

In this paper we uses KD-Tree search algorithm to carry on the adjacent node search for each samples of deformity strawberry and powdery mildew of strawberry image feature points, as it can be seen from the search nodes of the method has excellent speed and better matching accuracy. For higher classification accuracy characteristics to a large extent on behalf of the samples in the characteristic quantities have similar common, so a comprehensive analysis of the classification accuracy of each characteristic quantity, the final choice C6, C12, T8 is carried out as a combination of characteristics Search Match study.

However, we found that when searching neighboring nodes for most powdery mildew of strawberry image feature points, Euclidean distance are focused on the range of 0.00340927 to 0.0147406 in the correct match result and the average search node is 43.2, but when searching neighboring nodes for deformity strawberry image feature points, the Euclidean distance range are more dispersed in the correct match result and the average search node is 55.8.Through by study the size of characteristics we know that the reason why the above conditions are mainly attributed to different types of strawberries manifested differences of amount between the each type of feature.

\subsection{Conclusion}

From the above matching results, select three characteristic quantities(C6, C12, T8) as the searching and matching feature combination of strawberry powdery mildew achieve a better search result for matching accuracy, and the search matching accuracy for strawberry powdery mildew is $83.3 \%$, the deformity of strawberry matching accuracy reached $60.0 \%$, the number of nodes of powdery mildew strawberry the adjacent nodes search to be less than deformity strawberry, and it can be seen from the search nodes of the method has excellent speed and better matching accuracy but search for deformity strawberry rate has yet to be matched by choosing some other combination of improved features.

The reason for searching and matching of three-dimensional data instead of higher dimensional in this paper is for various characteristic quantities manifested classification characteristics by the cluster analysis through SPSS, but in order to improve search matching accuracy rate we can manually add a dimensional data and by changing the size of the data to improve search matching accuracy rate and the expense is to search for matching speed will be slower than before.

\section{References}

1. Du, Z., Li, D., et al.: Research on image matching algorithm based on KD-Tree search and SURF. Computer and Digital Engineering 40(2), 296-298 (2012)

2. $\mathrm{Wu}, \mathrm{H}$., Yang, K., et al.: Based on $\mathrm{KD}$ tree multidimensional index in a database application. Automation Technology and Application 26(9), 37-39 (2007) 
3. Aguilaa, J.J., Ariasb, E., Artigaoc, M.M., Mirallesc, J.J.: A distributed memory implementation of the False Nearest Neighbors method based on kd-tree applied to electrocardiography. Procedia Computer Science 1, 2579-2587 (2012)

4. Xi, Z.: Research and application of intelligent fault diagnosis system of wheat leaf disease. China University of science and technology, He Fei (2010)

5. Haralick: Statistical and Structural Approaches to Texture. Proc. IEEE 67, 786-804 (1979)

6. Bentley, J.L.: Multi dimensional binary search trees used for associative searching. Communications of the ACM, 509-217 (1975)

7. Ping, $\mathrm{X}$., $\mathrm{Xu}, \mathrm{L}$. : Huge amounts of data $\mathrm{K}$ neighboring new algorithm based on space partition. Journal of South China University of Technology (35), 65-70 (2007)

8. Zhang, Y., Li, M., Zhang, X., et al.: The greenhouse cucumber leaf nutrition information detection based on computer vision technology. Journal of Agricultural Engineering 21(8), 102-105 (2005)

9. Wang, J., Kong, B., Jia, Q.: Image retrieval techniques based on color feature 20(7), 160-164 (2011)

10. Gao, C., Hui, X.: Texture feature extraction based on gray level co-occurrence matrix. Computer System Application (19), 195-198 (2010)

11. Xiong, Y., Mao, Y., et al.: Application of the ordered KD-Tree on the image features matching. Chemical IndustryInstrument and Automation 37(10), 84-87 (2010)

12. Liu, Z., Zhang, Y.: Comprehensive utilization of color and texture features for image retrieval. Journal of Communication 20(5), 36-40 (1999)

13. Xiao, P., Xu, J., Chen, S.: Texture feature extraction method. Electronics Technology (6), 49-52 (2010)

14. Wu, F., Yang, Z., Zhu, H., Zheng, L., et al.: Review of the application of crop image classification and recognition based on color features. Review of China Agricultural Science and Technology 5(2), 76-79 (2003)

15. Zou, X.: Crop diseases and insect pests recognition based on computer vision research status. Computer Application 20(6), 238-242 (2011)

16. Tan, F., Ma, X.: Identification method based on the leaves of plant pests and diseases. Journal of Agricultural Mechanization Research (6), 41-43 (2009) 